\title{
Reducing emissions in New Zealand after Copenhagen
}

The outcomes from Copenhagen were less definite than many hoped. The major disappointment was in not achieving an internationally agreed $\mathrm{CO}_{2}$ reduction target, and everything else flowed from that, including not much progress towards international emissions trading.

But there were some good outcomes. From a New Zealand perspective the progress towards rules on land use was helpful. It is imperative that rural landowners are not unnecessarily hindered by unsympathetic rules preventing them from changing the use of their land from forestry to agriculture.

There was also a win for New Zealand in prompting the formation of a group of countries prepared to undertake research on science-led developments for agriculture. This research is crucial for New Zealand if we are to avoid our key export sector being penalised because of animal emissions. We are all looking forward to some scientific breakthroughs that can help us minimise this impact.

Phil O'Reilly is Chief Executive of Business New Zealand.
The importance of food security was also recognised. More generally, there were advancements in international thinking around relevant issues and a shared commitment to ongoing work. These are all positive.

We also learned more about what would be required to get emissions trading operating among more countries.

To a certain extent this boils down to future actions by the US and China. Because of the strengths of their respective economies both of these need to be involved to get other countries to sign up to any future international agreement.

During the Copenhagen meeting China assumed leadership of the developing nations in attendance, arguing that they should not be subject to independent verification of their emissions reductions.

This position was rejected by developed nations, led by the US. However, the US did not occupy a commensurate leadership role among developed nations, having arrived at the conference without a clear position on emissions reductions.

Without a domestic agreement on the issue, the US was not in a position to lead others on the global stage. Before the US can take that role in the future it must pass domestic legislation to limit emissions, and with increased political opposition to the Obama administration at home, this might not be easily achieved.

This does not mean we will never get international emissions trading. There is a groundswell in favour of it in many countries and some form of trade emerging between at least some nations is likely in the medium term. So should we, as some suggest, do nothing about reducing emissions?

This would be wrong. Regardless of what is happening on the international scene, it still makes sense to try and limit our greenhouse gas emissions, as a prudent precautionary measure prudent not only in terms of minimising risk to the environment, but also in terms of ensuring an environmentally positive brand for our exports.

This is the reason why the previous Labour-led government and the current 
National government both framed legislation for an ETS.

There is a great deal of difference between the scheme legislated for by the Labour-led Government and the one subsequently passed by the current National Government.

Labour's legislation would have capped the quantum of free carbon permits available to businesses, imposing enormous costs on the productive sector. Business NZ was extremely concerned at this prospect and committed a lot of time and resources to environmental and economic analysis and modelling to help ensure that these potential impacts were widely understood.

In particular, we were concerned that any proposed scheme should have an intensity-based allocation method for free carbon permits. Under this approach, emitted.

Importantly, National's emissions trading scheme has a built-in review mechanism so it can be improved according to changing circumstances. Relevant circumstances include whether and how many countries are also adopting emission reduction targets and moving to price $\mathrm{CO}_{2}$ into their economies. The first review will be next year.

While there are clear advantages in National's scheme in comparison with the previous one, many businesses will still have some doubts about having an ETS at all. In light of the failure of the Copenhagen process to reach any shared understanding on an early beginning to international emissions trading, this is understandable.

In Copenhagen's wake, the New Zealand scheme is one of only two

\section{There is an enormously increased sensitivity among consumers all around the world towards the need to go easy on the environment by producing goods and services with the smallest environmental footprint possible.}

at-risk enterprises would get a level of protection that would increase or decrease in step with production. In other words, under an intensity-based allocation method, enterprises would not be penalised for increases in productivity and economic growth would be encouraged, rather than penalised as it would have been under Labour's scheme.

National's scheme has incorporated the intensity-based approach and also has other features that reduce the risk to New Zealand enterprises. Notably, the price for carbon emissions will be limited to no more than $\$ 25$ per tonne of $\mathrm{CO}_{2}$ until the end of 2012. There will also be a further moderation of the price whereby permits to emit can be surrendered at a rate of one permit for every two tonnes of $\mathrm{CO}_{2}$ emitted - this effectively reduces the carbon price cap to $\$ 12.50$ per tonne formal schemes in existence, the other being the EU's. New Zealand's scheme is significantly more comprehensive than the EU's, in covering all greenhouses gases and all sectors including agriculture.

Clearly, the lack of international emissions trading partners is a key problem for New Zealand's scheme, and undoubtedly it will be high on the agenda in the first review of the scheme in 2011. The main problem with having an ETS in advance of many others in the world is that it will impose a price on carbon within the New Zealand economy, with there being no such additional cost in the economies of competitor nations. On an enterprise basis, it means New Zealand enterprises having to pay higher energy costs than competitor firms overseas from 1 July this year. The significance of this can hardly be overemphasised. It will have a major flow-on economic impact on every New Zealander.

Obviously, another matter to be considered in the ETS review next year will be whether its moderating mechanisms the carbon price cap and amount of free permit allocations - are adequate to offset this competitive disadvantage.

The fact that the Australian ETS has been put on the backburner will also need to be considered by the review. There is thus a need for some caution as the future shape of our ETS is considered. But we should not lose sight of the fact that there are significant benefits to New Zealand's actions to date towards reducing carbon emissions.

Being able to attract consumers who want low-carbon goods and services is extremely important. There is an enormously increased sensitivity among consumers all around the world towards the need to go easy on the environment by producing goods and services with the smallest environmental footprint possible. No longer confined to a small greenie fringe, this is now a mainstream movement. Household shoppers, mothers, kids and more are all making their preferences felt.

The recent debate about palm oil in chocolate and use of palm kernels as feedstock is a good example of consumers refusing to accept a product they viewed as environmentally undesirable.

Consumer groups can now influence customers almost instantaneously via the internet. The ability for certain products to be blacklisted all around the world within a matter of hours or days is a huge power that can make or break a product or a brand.

New Zealand producers have the opportunity to be ahead of the curve and ensure their products are acceptable to this huge and growing market for sustainability. This is the context in which we should view New Zealand's steps so far towards emissions reductions including our work towards an ETS. Of course, reducing emissions doesn't begin and end with emissions trading - there are many ways in which we can stem emissions growth, all capable of bringing extremely positive environmental branding for us. The low-carbon challenge brings a 
number of difficulties but many of these will also have the effect of sharpening our abilities and our wits.

What will we need to be able to take advantage of the opportunities furnished by this change in customer desires? Key factors will be innovation, science, technology and skills. These aren't things that come in a box - they are the outcomes of a good education system and good science and innovation frameworks.

We will need to focus hard on the kinds of skills that come out of our high schools and tertiary education institutions and will need to ensure that we have enough science graduates and enough opportunities for them to contribute and innovate.

These are areas where as a nation we have quite a bit of work to do. And for individual businesses, adaptability will be important. Businesses that will succeed best will be those that can adapt, adopt new technologies, and create new products and services that are fit for new consumer desires.
The Copenhagen conference failed to get an agreed reduction target or international ETS in the short term, but for the long term it has signalled that the nations and consumers of the world care greatly about environmental sustainability. How New Zealand producers react to that signal will make a big difference to our economic sustainability.

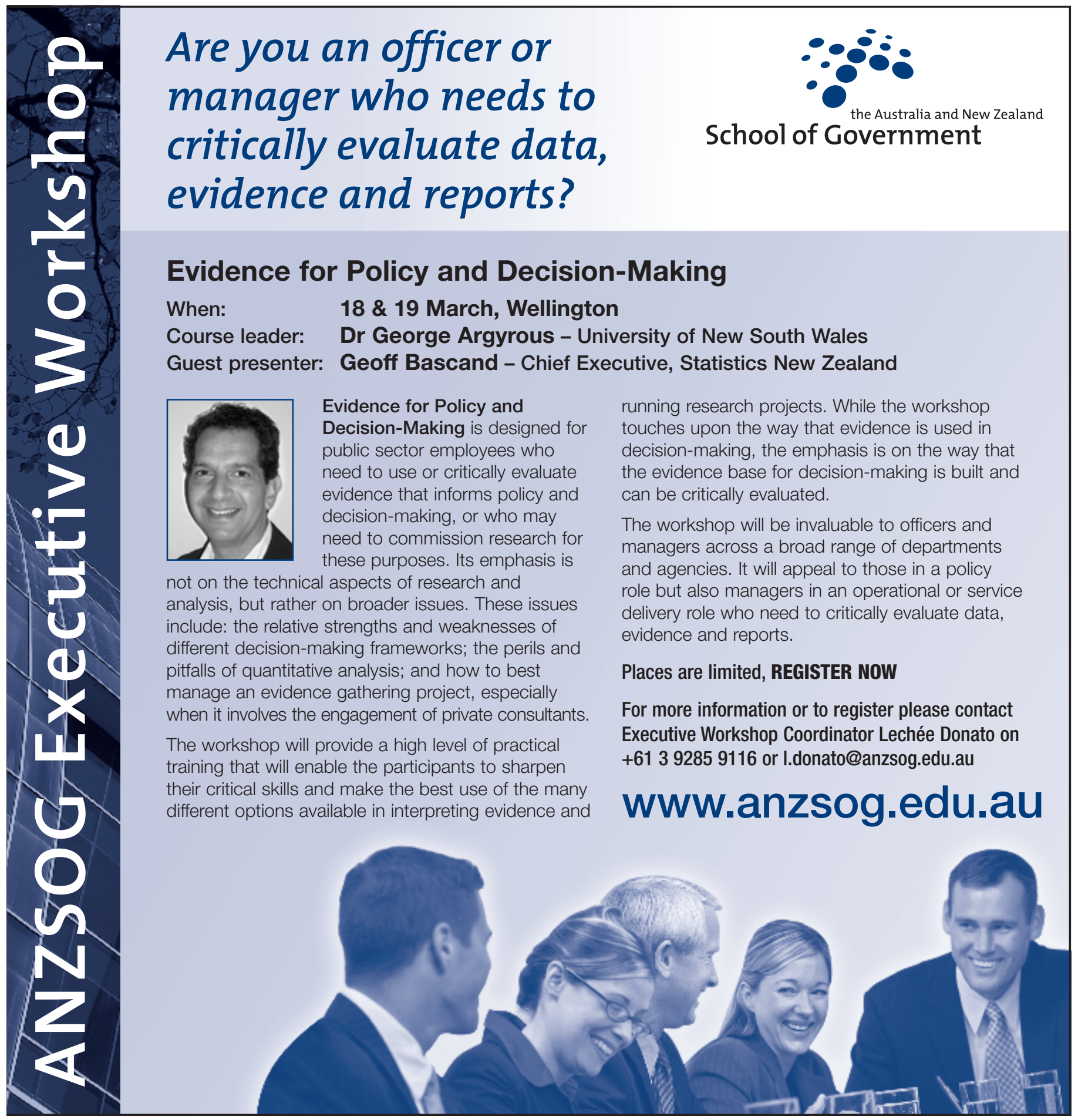

